\title{
Dependencia, interdependencia, autonomía
}

\section{Dependence, interdependence, autonomy}

\section{Palabras clave}

Dependencia, interdependencia, autonomía, receptividad, solidaridad, apoyos.

\section{Keywords}

Dependence, interdependence, autonomy, receptivity, solidarity, supports.

\section{Xabier Etxeberria Mauleon} <xetxemau@deusto.es>

Universidad de Deusto. España

\section{Introducción ${ }^{1}$}

Dependencia, interdependencia y autonomía definen, en medida decisiva, cómo somos los humanos. Para entender adecuadamente cada una de estas categorías, para no caer en graves errores con consecuencias prácticas, es necesario entenderla imbricada con las otras dos, siempre. Dicho en positivo: percibirlas interrelacionadas en sus justas dinámicas posibilitará que nos conozcamos en lo que somos y que nuestras relaciones sean fecundas. Para quien trabaja en la acción social, en cualquiera de sus ámbitos, es fundamental hacerse cargo de ello.

\section{En la base, nuestra condición humana de dependientes}

Nuestra condición de dependientes se manifiesta especialmente en las etapas iniciales y finales de nuestra biografía, pero es una constante de nuestras vidas. Somos, siempre, dependientes de los otros (y de lo otro no

1. Texto base de la intervención (el 6-10-2020) en un curso de verano de la Universidad del País Vasco (UPV), realizado en Bilbao, sobre "Ética y diversidad en la acción social".

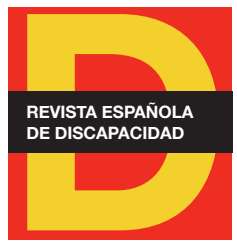

Para citar:

Etxeberria, X. (2021). Dependencia, interdependencia, autonomía. Revista Española de Discapacidad, 9(1), pp. 241-246.

Doi: <https://doi.org/10.5569/23405104.09.01.12>

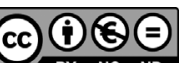


humano). No solo les necesitamos para afrontar nuestra fragilidad y vulnerabilidad y cubrir nuestras necesidades con las que desarrollar nuestras capacidades (inclúyase la necesidad de amparo cultural); también para ejercer estas últimas y alcanzar nuestras aspiraciones.

Esta condición de dependencia revela una disposición básica en nosotros, que modula la propia configuración de nuestro cuerpo y nuestra psique: la de la receptividad de lo que nos llega de los otros y de lo otro, sin lo que no podemos vivir ni desarrollarnos. En su expresión positiva nos adviene como don (aunque también, no hay que olvidarlo, estamos abiertos a recibir el impacto de lo malo). Educarnos para la vida plena del ser autónomo es, primariamente, educarnos para una receptividad que dura toda la vida.

Somos también seres capaces, algo igualmente fundamental. Pero no debe olvidarse que las capacidades (entre ellas, la libertad que se autodetermina) se desarrollan gracias a las receptividades, y se expresan decisivamente no como creación pura del sujeto, sino como responsividad (creativa) a las recepciones.

El ideal liberal del "individuo separado, libre y autosuficiente, que entra en relaciones de fondo contractual con quienes quiere" es como tal inconsistente, aunque haya servido para subrayar el valor de la autonomía ( $\sin$ que deban olvidarse sus excesos). Ignora la inevitabilidad de todas esas recepciones y su dimensión de don.

Un daño "colateral" de ese ideal es el rechazo y menosprecio de la dependencia como tal. En sí es rechazo y menosprecio de la condición humana. A nivel personal, refleja soberbia, con frecuencia fatua, y siempre falsa, por ignorante. Lo doloroso y moralmente intolerable es cuando se expresa como rechazo y menosprecio de personas concretas por sus dependencias concretas.

Desde este punto de partida, reconocer nuestra condición de dependencia implica humildad, en el sentido de aceptación lúcida de nuestra limitación. Pero invita también a abrirse a la positividad de la condición de dependencia. Intrínseca a esta se dan: a) la apertura a la solidaridad fáctica, llamada a concretarse como solidaridad moral; b) la relacionalidad de la solicitud con quienes nos atienden en la dependencia, con quienes atendemos en su dependencia. Esta solicitud es el momento ético primario, sobre el que hay que construir la justicia debida a toda persona, sujeto de dignidad: como exigencia, garantizada institucionalmente, cuando el respeto a esa dignidad falla; como justicia compasiva, completando plenamente la atención en la síntesis tensional de sus dos perspectivas, cuando no falla.

\section{Sobre las personas llamadas dependientes}

La concreción de nuestras dependencias varía entre nosotros y varía también en cada uno de nosotros a lo largo de nuestra vida. Esto supone que la dependencia es una de las variables que nos hace diversos: iguales en nuestra condición de dependientes, diversos en la especificidad de nuestras dependencias.

Ahora bien, hay algunas modalidades de dependencia que son especialmente resaltadas en la sociedad: aquellas que se prolongan en el tiempo de forma durable, que no decrecen en lo básico (sí pueden crecer) y que requieren apoyos no solo de instrumentos en sentido amplio sino (sobre todo) de otras personas. Es 
a las personas que las viven a las que llamamos "dependientes". Un uso así de la palabra tiene dos riesgos: el de reducir la identidad de la persona a su dependencia y el de ocultar el hecho de que dependientes lo somos todos.

Para medir el alcance que el primer riesgo tiene, conviene hacerse cargo de que el rasgo que define la diversidad en la dependencia remite a limitación de alguna capacidad en la iniciativa del sujeto. Por sentido ajustado de la realidad, ni debe desmesurarse, identificando a la persona con la limitación concebida rígidamente, ni debe ignorarse, reduciendo la diversidad a mera diferencia irrelevante para las capacidades. Si se cae en lo primero, se define a la persona por la carencia, se la menosprecia como persona, dañando su dignidad, y en consecuencia, se la margina, atendiéndola a lo más con paternalismo benevolente. Si se cae en lo segundo, queda sin fundamento el derecho a los apoyos.

En cuanto al riesgo de ocultar el hecho de que dependientes somos todos, es importante que esto no se olvide, que no se olvide la solidaridad en interdependencias a la que ello nos convoca (retomaré luego este dato). Por eso, en las personas con dependencias que resaltamos socialmente, debemos ver la revelación de nuestra condición compartida de seres dependientes. Ahora bien, tampoco tenemos que trivializar este dato para ignorar que unas dependencias piden más atención que otras, más ayuda a la gestión personal de ellas que otras.

Todo esto nos muestra que tenemos que matizar el ideal de independencia. Es bueno anhelarlo y avanzar hacia él, saber que podemos ser creativos y originales. Pero si lo absolutizamos, aparte de no ser honestos con la verdad, a quien por sus modalidades de dependencia se va a encontrar con limitaciones significativas de posibilidades se le empuja a la frustración. El ideal propiamente dicho es el ideal de bien -en el que están implicados los otros - , con las capacidades que podamos desarrollar recibiendo los apoyos que precisemos. Formulado de otro modo: el ideal no es la independencia sino la no dominación (en sus formas de manipulación, discriminación, exclusión, opresión o violencia), para que no se bloqueen nuestras posibilidades, acompañado de los apoyos que se precisen para realizarlas.

A veces las dependencias se hacen tan grandes que toda posibilidad de iniciativa parece acallarse. Piénsese en una persona con Alzheimer avanzado. Realidades como esta nos muestran que, si la autonomía es muy importante para la vida ética, la focalidad última de esta se encuentra en la dignidad. Si no la vemos plena en esa persona, más manifiesta si cabe que en la persona más autónoma, algo nos falla gravemente. Y el que la veamos en ella, nos ayudará a percibir secretos rescoldos de la capacidad de autonomía que tuvo, huellas indelebles de ella en su corporalidad viviente. Cuidarla en su dependencia, realizar con ella la justicia compasiva, brotará entonces con naturalidad, aunque resulte costoso. Algo similar podría decirse de otras situaciones parecidas de dependencia.

Estas consideraciones en modo alguno ponen en cuestión que el primer objetivo de la planificación institucional y de la atención directa a las personas con las dependencias que estamos comentando tiene que ser la potenciación máxima posible de su autodeterminación, siendo solo segundo -aunque no secundario sino muy relevante también - la acogida y cuidado ante la limitación remanente de ella. De todos modos, en la praxis del cuidado tenderán a imbricarse ambos objetivos. 


\section{Sobre nuestra interdependencia}

De lo antedicho se desprende que nuestra realidad fundamental a lo largo de toda nuestra vida no es la dependencia ni la independencia, sino la interdependencia. Somos seres con dependencias (que reclaman ayuda, necesitados de recibir apoyos) y con capacidades (que pueden ofrecerla, que pueden dar esos apoyos). Imbricadas entre nosotros e incluso dentro de nosotros, se plasman en una solidaridad fáctica de interdependencia que, como adelanté, tenemos que desarrollar en solidaridad moral.

Esta interdependencia se expresa a nivel cívico global, a nivel de grupos concretos y a nivel de relaciones interpersonales. Tiene una expresión institucional, muy compleja en sociedades como las nuestras, y una expresión intersubjetiva, insertada con más o menos intensidad en esas instituciones.

En la concreción de nuestras interdependencias a lo largo de nuestra vida, hay variaciones que se hacen eco de las antes subrayadas sobre nuestras dependencias. En nuestras relaciones de interdependencia, en unas ocasiones nos corresponde más recibir que dar, en otras, más dar que recibir. Es de todos modos complicado separar ambos aspectos cuando consideramos que no solo se dan bienes empíricamente constatables, también bienes no constatables, inmateriales. Lo que abre, por ejemplo, a que quien recibe, ya en el modo de recibir y sin pretenderlo, nos dé. La cuantificación se nos escapa. Y lo ideal es que no pretendamos entrar en ella, que acojamos positivamente tanto el dar como el recibir (con frecuencia, psicológicamente, algo más difícil que el dar), sabiendo además que en el sustrato de eso que tenemos y damos hay mucho de recibido. En definitiva, sabiendo que todas las personas damos y recibimos, lo que es importante para nuestra vida realizada.

La dinámica de interdependencia se realiza en múltiples realidades. Por poner algunos ejemplos, tanto en los impuestos que pagamos, que en justicia tendrían que ser proporcionales a lo que tenemos, como en nuestras tareas profesionales en el campo de la acción social, como en los cuidados que damos o recibimos de un familiar.

En la solidaridad fáctica de la interdependencia que no se ha desarrollado en solidaridad moral cabe lo malo, el mal: que el que tiene más poder, institucional o personal, lo utilice para manipular, discriminar, marginar, explotar a quien no lo tiene, quien, en ocasiones, depende además de él para afrontar sus limitaciones. Se impone entonces de nuevo, para evitarlo, la dimensión normativa de la ética -apoyada en el valor de la dignidad - como respeto y justicia, con su expresión jurídica cuando se precise.

En nosotros no solo se da interdependencia interhumana. La hay también con realidades no humanas y con la naturaleza como tal. Con frecuencia está relacionada con la interdependencia interhumana y está siendo cada vez más relevante. Pero esto nos introduce en otra problemática que no nos toca abordar aquí. Quede solo apuntada para destacar lo complejo y lo decisivo de nuestra realidad de interdependencia. 


\section{Sobre la autonomía}

La capacidad de autonomía es muy importante. Cuando se ejerce de forma completa (como debería ser siempre que esté en juego alguna cuestión relevante), implica un complejo proceso de discernimiento, valoración (de la iniciativa, de las circunstancias en las que hay que realizarla, de las consecuencias previsibles), elección-decisión y ejecución. Involucra así al conjunto de nuestras capacidades psíquicas y corporales, en formas que deben ser articuladas y armonizadas. Puede, además, ejercerse de modo individual o grupal, como consenso entre autonomías individuales. Y ejercerse tanto en ámbitos privados, como sociales, como públicos.

Implica que lo que decidimos-hacemos pueda ser considerado realmente "nuestro", que sea nuestra iniciativa: podemos reclamarlo así, pero también debemos responder de ello ante los demás. La autonomía nos hace moralmente responsables.

Ahora bien, que nuestros actos autónomos sean nuestros (autos) no significa, con todo, que sean pura y duramente nuestros. En ellos hay presupuestas muchas recepciones de dones de otros; la novedad que ponemos se asienta en ellos. Este reconocimiento, por un lado, modula nuestras reclamaciones de apropiación y, por otro, nos hace percibir la presencia del otro y lo otro (hetero) en el autos. Por eso, aunque suene primariamente a contradicción, un autor ha propuesto con acierto hablar de "heteroautonomía".

La autonomía se relaciona con la temática de este curso - la diversidad - en cuanto es factor muy relevante de la diversidad personal, de la construcción de la diversidad entre las personas. Aporta a la formación de la identidad personal, que tiene múltiples fuentes conexionadas con los otros y con las pertenencias comunitarias, lo que es más singular de ella, la iniciativa del sujeto.

La autonomía es una capacidad abierta a crecimientos y decrecimientos. Está condicionada por factores externos que le ofrecen mayores o menores oportunidades y por las modalidades subjetivas de dependencia que se tengan. Ofrecer apoyos y acompañamientos para enfrentarse positivamente a esta realidad, a fin de que se desarrolle y ejerza lo más plenamente posible - en el crecer y en el decrecer-, siempre en el respeto de la autonomía que el otro tenga, es una finalidad clave de múltiples compromisos profesionales, en cada uno de acuerdo con su fin profesional propio.

He aquí, de cara a estos apoyos, unas mínimas pautas éticas, apoyadas en algunas distinciones:

- Conviene distinguir entre capacidad para decidir y autosuficiencia para ejecutar. Cuando se da lo primero y no lo segundo, se impone: respetar la decisión y ayudar en la ejecución; y no hacer del entrenamiento en destrezas un sustituto del apoyo en la capacidad de decisión.

- Distinguir capacidad de autodeterminación actual, la que se tiene en el presente, y capacidad de autodeterminación potencial, la que se puede tener con apoyos. La que primariamente debe ser respetada es la segunda, esto es, no se debe sustituir la autodeterminación de quien ahora no puede decidir algo, si podría decidirlo si se le ofrecieran apoyos. Hay que comenzar por estos para que luego la persona decida todo lo que es posible para ella.

- Distinguir: a) autodeterminación como libre arbitrio, esto es, sin que reclame obligadamente procesos de discernimiento previo: conviene ayudar a que este se dé cuando la cuestión es relevante; b) autono- 
mía como autolegislación, esto es, darse la propia ley moral: ayudar a que se tome conciencia de que se impone hacerlo con justeza moral siempre que implique derechos y deberes, de los demás y propios; c) autonomía como autenticidad - ser uno mismo - , la que afecta a los proyectos de vida: ayudar a que se decidan y realicen en función de lo que nos sentimos llamados a ser, de lo que nos construirá en nuestra verdad.

Espero que con esta exposición hayan quedado patentes las complejas interconexiones existentes entre dependencia, interdependencia y autonomía. Y cómo estas, por un lado, dan cuenta de nuestra condición compartida de humanidad - nos afectan a todos - y, por otro, nos ofrecen el marco, la inspiración y la motivación en los que tenemos que situar nuestros compromisos en la acción social.

\section{Nota bibliográfica}

He abordado ampliamente esta temática, en su fundamentación y en sus desarrollos, en: Etxeberria, X. (2020). Dependientes, vulnerables, capaces. Receptividad y vida ética. Catarata.

Presento de forma más completa y aplicada las distinciones relativas a la autodeterminación y los criterios que pautan los apoyos, orientados a colectivos concretos en: Etxeberria, X. (2016). Autonomía y decisiones de representación/sustitución en personas con discapacidad intelectual. Perspectiva ética. Siglo Cero, 47(1), pp. 55-66; y en Etxeberria, X. (2017). Acompañar en la fragilidad y la vulnerabilidad a los ancianos enfermos y pacientes con demencias. Labor Hospitalaria, 318(2), pp. 42-47.

Para ahondar en las diversas versiones de la autodeterminación puede consultarse: Kant, I. (1973). Fundamentación de la metafísica de las costumbres. Espasa Calpe; Mill, J. S. (1970). Sobre la libertad. Alianza; Taylor, C. (1994). Ética de la autenticidad. Paidós.

Se presenta la libertad como no dominación en Pettit, P. (1999). Republicanismo. Una teoría sobre la libertad y el gobierno. Paidós. 